CAOS 2017. 17th Annual Meeting of the International Society for Computer Assisted Orthopaedic Surgery

\title{
Patient specific instrumentation influences hemoglobin decrease after total knee replacement
}

\author{
Davide Cucchi ${ }^{1,2^{*}}$, Beatrice Zanini ${ }^{1}$, Paolo Ferrua ${ }^{3}$, \\ Riccardo Compagnoni ${ }^{1}$, Alessandra Menon ${ }^{1,2}$, Pietro Randelli ${ }^{1,2}$ \\ ${ }^{1}$ Dipartimento di Scienze Biomediche per la Salute, \\ Università degli Studi di Milano \\ ${ }^{2}$ U.O.C. $1^{\circ}$ Divisione, A.S.S.T. Centro Specialistico \\ Ortopedico Traumatologico Gaetano Pini-CTO \\ ${ }^{3}$ SSD Chirurgia Articolare del Ginocchio, A.S.S.T. Centro Specialistico \\ Ortopedico Traumatologico Gaetano Pini-CTO \\ d.cucchi@tiscali.it
}

\begin{abstract}
Patient Specific Instrumentation (PSI) may contribute to reduce blood loss after total knee replacement (TKR) by avoiding violation of the medullary canal. The purpose of the study was to compare the hemoglobin $(\mathrm{Hb})$ decrease in two groups of patients undergoing TKR with PSI and conventional instrumentation.

Pre- and post-operative blood samples were collected for twenty-two patients randomly assigned to receive a PSI-assisted or conventional TKR. Post- to preoperative $\mathrm{Hb}$ difference was calculated.

A significant difference in $\mathrm{Hb}$ reduction in favor of the PSI group was registered on the last day of stay but not on the previous post-operative days: these promising results suggest a beneficial effect of PSI in blood loss reduction. PSI may hence be considered among the strategies available to control and reduce blood loss related to TKR.
\end{abstract}

\section{Introduction}

Blood loss in total knee replacement (TKR) is related to longer hospital stay and rehabilitation, higher rate of infections and transfusions and increased overall morbidity ${ }^{1-3}$. Patient Specific Instrumentation (PSI) is supposed to contribute to blood loss reduction by avoiding the use of intramedullary guides. Aim of this study is to investigate differences in blood loss related parameters 
PSI influences Hb decrease after TKR. Cucchi, Zanini, Ferrua, Compagnoni, Menon and Randelli

between patients who received PSI-assisted TKR and a control group of conventionally implanted TKRs.

\section{Materials and methods}

Goal of this study was to compare the estimated hemoglobin $(\mathrm{Hb})$ decrease in two groups of patients undergoing TKR with PSI and conventional instrumentation.

Twenty-four patients were prospectively enrolled and randomized. A cemented prosthesis with patellar resurfacing was implanted using the same sequence of soft-tissue release. Conventional cutting instruments were used in the control group and PSI cutting guides (Trumatch, DePuy) were used in the treatment group. Surgical technique, anesthetic and pain-control medications, antithrombotic and antibiotic prophylaxes and rehabilitation procedures were standardized according to the institution's internal protocols. Blood samples for determination of $\mathrm{Hb}$ levels were collected pre-operatively and on $1^{\text {st }}, 2^{\text {nd }}, 3^{\text {rd }}$, and last day $\left(5^{\text {th }} \pm 1\right.$ day).

Statistical analysis was performed using GraphPad Prism v 6.0 software (GraphPad Software Inc.). The differences for continuous variables was proved with an unpaired Student's t-test. The significance level was set at p-value lower than 0.05 .

\section{Results}

Twenty-two patients completed the follow-up. A significant difference in Hb reduction in favor of the PSI group was registered on the last day of stay $(\mathrm{p}<0.01)$ but not on the previous post-operative days (p: n.s.).

\section{Discussion}

The main finding of our study was that PSI can reduce postoperative $\mathrm{Hb}$ decrease. Since $\mathrm{Hb}$ decrease may cause short- and long-term complications numerous strategies were developed to reduce it ${ }^{2,45-13}$. PSI overcomes the need of violating the medullary canal (which can increase the risk of perioperative blood loss and embolization of medullary content), making reasonable to expect a reduction in blood loss ${ }^{14-18}$.

A reduction in intra- or peri-operative blood loss with PSI was observed in multiple reports ${ }^{15,19-23}$, while other authors have failed to observe significant differences $1,2,17,20,21,24-34$. However, only a handful of clinical studies exist, which were specifically designed to investigate peri-operative blood loss after TKR with PSI. ${ }^{1-3,35-37}$.

When comparing PSI with conventional instrumentation, Pietsch found a significant difference in the drainage loss but not in $\mathrm{Hb}$ loss and transfusions requirements ${ }^{1}$ while Rathod identified a non significant trend towards lower $\mathrm{Hb}$ drop in bilateral procedures with PSI ${ }^{37}$. Thienpont and Cundy could not detect significant differences in either blood-loss-related parameters or transfusions requirements ${ }^{2,36}$. Schwarzkopf described a significant decrease in intra-operative blood loss for PSI but did not analyze any peri-operative variables ${ }^{3}$. Comparing PSI to computer-assisted surgery, León reported a significant difference in total blood loss and transfusion requirements in favor to PSI ${ }^{35}$. 
PSI influences Hb decrease after TKR. Cucchi, Zanini, Ferrua, Compagnoni, Menon and Randelli

This study, which prospectively investigated the treatment effect on post-operative $\mathrm{Hb}$ decrease, showed a significant difference in Hb reduction in favor of the PSI group on the last day of hospital stay but was not able to confirm a difference in the previous days.

Limitations in this study are the relatively small sample size and the absence of an intra-operative esteem of blood loss. Furthermore, a single type of PSI was tested; other systems may perform differently and these results may then not be representative for all different custom-fit technologies available.

\section{Conclusions}

A significant difference in hemoglobin reduction on the last day of stay was reported in the group treated with, results which need to be confirmed by adequately powered future studies.

\section{References}

1. Pietsch M, Djahani O, Zweiger C, Plattner F, Radl R, Tschauner C, et al. Custom-fit minimally invasive total knee arthroplasty: effect on blood loss and early clinical outcomes. Knee Surgery, Sport Traumatol Arthrosc 2013;21(10):2234-2240.

2. Thienpont E, Grosu I, Paternostre F, Schwab P-E, Yombi JC. The use of patient-specific instruments does not reduce blood loss during minimally invasive total knee arthroplasty? Knee Surg Sports Traumatol Arthrosc 2014;2055-2060.

3. Schwarzkopf R, Brodsky M, Garcia GA, Gomoll AH. Surgical and Functional Outcomes in Patients Undergoing Total Knee Replacement With Patient-Specific Implants Compared With 'Off-the-Shelf' Implants. Orthop J Sport Med 2015;3(7):2325967115590379.

4. Sehat, Evans, Newman. How much blood is really lost in total knee arthroplasty?. Correct blood loss management should take hidden loss into account. Knee 2000;7(3):151-155.

5. Watts CD, Pagnano MW. Minimising blood loss and transfusion in contemporary hip and knee arthroplasty. J Bone Joint Surg Br 2012;94(11 Suppl A):8-10.

6. Tai T-W, Lin C-J, Jou I-M, Chang C-W, Lai K-A, Yang C-Y. Tourniquet use in total knee arthroplasty: a meta-analysis. Knee Surgery, Sport Traumatol Arthrosc 2011;19(7):11211130 .

7. Tai T-W, Chang C-W, Lai K-A, Lin C-J, Yang C-Y. Effects of tourniquet use on blood loss and soft-tissue damage in total knee arthroplasty: a randomized controlled trial. J Bone Joint Surg Am 2012 ;94(24):2209-15.

8. Plymale MF, Capogna BM, Lovy AJ, Adler ML, Hirsh DM, Kim SJ. Unipolar vs bipolar hemostasis in total knee arthroplasty: a prospective randomized trial. J Arthroplasty 2012;27(6):1133-7.e1.

9. He P, Zhang Z, Li Y, Xu D, Wang H. Efficacy and Safety of Tranexamic Acid in Bilateral Total Knee Replacement: A Meta-Analysis and Systematic Review. Med Sci Monit 2015;21:3634-3642.

10. Fu X, Tian P, Xu G-J, Sun X-L, Ma X-L. Thrombin-Based Hemostatic Agent in Primary Total Knee Arthroplasty. J Knee Surg 2016 ;30(2)121-127. 
PSI influences Hb decrease after TKR. Cucchi, Zanini, Ferrua, Compagnoni, Menon and Randelli

11. Kim HJ, Fraser MR, Kahn B, Lyman S, Figgie MP. The Efficacy of a Thrombin-Based Hemostatic Agent in Unilateral Total Knee Arthroplasty. J Bone Jt Surgery-American Vol $2012 ; 94(13): 1160-1165$.

12. Randelli F, D'Anchise R, Ragone V, Serrao L, Cabitza P, Randelli P. Is the newest fibrin sealant an effective strategy to reduce blood loss after total knee arthroplasty? A randomized controlled study. J Arthroplasty $2014 ; 29(8): 1516-20$.

13. Wang H, Shan L, Zeng H, Sun M, Hua Y, Cai Z. Is fibrin sealant effective and safe in total knee arthroplasty? A meta-analysis of randomized trials. J Orthop Surg Res 2014;9(1):36.

14. Nunley RM, Ellison BS, Ruh EL, Williams BM, Foreman K, Ford AD, et al. Are patientspecific cutting blocks cost-effective for total knee arthroplasty? Clin Orthop Relat Res 2012;470(3):889-94.

15. Boonen B, Schotanus MGM, Kort NP. Preliminary experience with the patient-specific templating total knee arthroplasty. Acta Orthop 2012;83(4):387-93.

16. Ng VY, DeClaire JH, Berend KR, Gulick BC, Lombardi A V. Improved accuracy of alignment with patient-specific positioning guides compared with manual instrumentation in TKA. Clin Orthop Relat Res 2012;470(1):99-107.

17. Noble JW, Moore CA, Liu N. The value of patient-matched instrumentation in total knee arthroplasty. J Arthroplasty 2012;27(1):153-5.

18. Tibesku CO, Hofer P, Portegies W, Ruys CJM, Fennema P. Benefits of using customized instrumentation in total knee arthroplasty: results from an activity-based costing model. Arch Orthop Trauma Surg 2013;133(3):405-11.

19. Ferrara F, Cipriani A, Magarelli N, Rapisarda S, Santis V De, Burrofato A, et al. Implant Positioning in TKA: Comparison Between Conventional and Patient-Specific Instrumentation. Orthopedics 2015;38(4):e271-e280.

20. Chotanaphuti T, Wangwittayakul V, Khuangsirikul S, Foojareonyos T. The accuracy of component alignment in custom cutting blocks compared with conventional total knee arthroplasty instrumentation: prospective control trial. Knee 2014;21(1):185-8.

21. Boonen B, Schotanus MGM, Kerens B, Weegen W van der, Drumpt R a M van, Kort NP. Intra-operative results and radiological outcome of conventional and patient-specific surgery in total knee arthroplasty: a multicentre, randomised controlled trial. Knee Surg Sports Traumatol Arthrosc 2013;21(10):2206-12.

22. Nabavi A, Olwill CM. Early outcome after total knee replacement using computed tomography-based patient-specific cutting blocks versus standard instrumentation. J Orthop Surg (Hong Kong) 2015;23(2):182-4.

23. Vide J, Freitas TP, Ramos A, Cruz H, Sousa JP. Patient-specific instrumentation in total knee arthroplasty: simpler, faster and more accurate than standard instrumentation-a randomized controlled trial. Knee Surgery, Sport Traumatol Arthrosc 2015. DOI: 10.1007/s00167-0153869-0

24. Kotela A, Lorkowski J, Kucharzewski M, Wilk-Frańczuk M, Śliwiński Z, Frańczuk B, et al. Patient-Specific CT-Based Instrumentation versus Conventional Instrumentation in Total Knee Arthroplasty: A Prospective Randomized Controlled Study on Clinical Outcomes and In-Hospital Data. Biomed Res Int 2015;2015:165908.

25. Shen C, Tang Z-H, Hu J-Z, Zou G-Y, Xiao R-C, Yan D-X. Patient-specific instrumentation 
PSI influences Hb decrease after TKR. Cucchi, Zanini, Ferrua, Compagnoni, Menon and Randelli

does not improve accuracy in total knee arthroplasty. Orthopedics 2015;38(3):e178-88.

26. Spencer B a., Mont M a., McGrath MS, Boyd B, Mitrick MF. Initial experience with customfit total knee replacement: Intra-operative events and long-leg coronal alignment. Int Orthop 2009;33(6):1571-1575.

27. Voleti PB, Hamula MJ, Baldwin KD, Lee G-C. Current Data Do Not Support Routine Use of Patient-Specific Instrumentation in Total Knee Arthroplasty. J Arthroplasty 2014;29(9):17091712.

28. DeHaan AM, Adams JR, DeHart ML, Huff TW. Patient-Specific Versus Conventional Instrumentation for Total Knee Arthroplasty: Peri-Operative and Cost Differences. $J$ Arthroplasty 2014;29(11):2065-2069.

29. Renson L, Poilvache P, Wyngaert H Van den. Improved alignment and operating room efficiency with patient-specific instrumentation for TKA. Knee 2014;21(6):1216-20.

30. Roh YW, Kim TW, Lee S, Seong SC, Lee MC. Is TKA using patient-specific instruments comparable to conventional TKA? A randomized controlled study of one system knee. Clin Orthop Relat Res 2013;471(12):3988-3995.

31. Zhu M, Chen JY, Chong HC, Yew AKS, Foo LSS, Chia S-L, et al. Outcomes following total knee arthroplasty with CT-based patient-specific instrumentation. Knee Surg Sports Traumatol Arthrosc 2015;1-6.

32. Chareancholvanich K, Narkbunnam R, Pornrattanamaneewong C. A prospective randomised controlled study of patient-specific cutting guides compared with conventional instrumentation in total knee replacement. Bone Joint J 2013;95-B(3):354-9.

33. Vundelinckx BJ, Bruckers L, Mulder K De, Schepper J De, Esbroeck G Van. Functional and radiographic short-term outcome evaluation of the visionaire system, a patient-matched instrumentation system for total knee arthroplasty. J Arthroplasty 2013;28(6):964-970.

34. Predescu V, Prescura C, Olaru R, Savin L, Botez P, Deleanu B. Patient specific instrumentation versus conventional knee arthroplasty: comparative study. Int Orthop 2016. DOI: $10.1007 / \mathrm{s} 00264-016-3356-3$

35. León VJ, Lengua MA, Calvo V, Lisón AJ. Use of patient-specific cutting blocks reduces blood loss after total knee arthroplasty. Eur J Orthop Surg Traumatol 2017;27(2):273-277.

36. Cundy WJ, Theodoulou A, Ling CM, Krishnan J, Wilson CJ. Blood Loss in Total Knee Arthroplasty. J Knee Surg 2016 . DOI: 10.1055/s-0036-1592147

37. Rathod PA, Deshmukh AJ, Cushner FD. Reducing blood loss in bilateral total knee arthroplasty with patient-specific instrumentation. Orthop Clin North Am 2015;46(3):343-50, ix. 